\title{
O uso da farinha de peixe na alimentação de poedeiras como fonte enriquecedora de
}

\section{OVOS}

The use of fish flour in the feed of layers as enriching source of eggs

El uso de harina de pescado en la alimentación de gallinas ponedoras como fuente enriquecedora de huevos

Talitha Kássia Alves dos Santos Dessimoni ORCID: https://orcid.org/0000-0001-7352-5690 Universidade José do Rosário Vellano, Brasil E-mail: talithalves@gmail.com

Edina de Fátima Aguiar

ORCID: https://orcid.org/0000-0002-7883-5628 Universidade José do Rosário Vellano, Brasil E-mail: edina.aguiar@unifenas.br

\begin{abstract}
Resumo
Devido à eficácia na prevenção de doenças e promoção da saúde, o consumo de alimentos funcionais e nutracêuticos têm aumentado cada vez mais. Nesse sentido, o ovo se inclui nessa classe de alimentos, pois é uma das fontes mais econômicas de proteína para a dieta humana, possui em sua composição lipídios, vitaminas e minerais de alta qualidade. Os ovos apresentam alto potencial para enriquecimento com ácidos graxos polinsaturados (PUFAs) através da suplementação da dieta de galinhas poedeiras com ingredientes que contenham esse tipo de ácido graxo, resultando no aumento da deposição de ômega-3 na gema dos ovos. A farinha de peixe é um exemplo de ingrediente que pode ser incluído às dietas avícolas, pois possui quantidade considerável de aminoácidos, vitaminas e PUFAs. A inclusão da farinha de peixe em dietas de poedeiras pode melhorar a resposta imune das aves e em humanos, os PUFAs auxiliam na prevenção e tratamento de diversas doenças, diminui níveis de triglicerídeos circulantes e participa da estrutura e função do cérebro. Além da fácil inclusão em dietas de poedeiras, a farinha de peixe promove rápida modificação na composição lipídica da gema do ovo e ajuda no escoamento de resíduos de agroindústrias. Foi realizada uma pesquisa bibliográfica pela internet de artigos relacionados a inclusão de farinha de peixe na alimentação de poedeiras dos anos 2005 a 2020. O objetivo do presente trabalho foi encontrar pontos positivos que alavanquem o uso desse subproduto em dietas avícolas.
\end{abstract}

Palavras-chave: Ômega-3; PUFAs; Resíduos de peixe.

\begin{abstract}
Due to the effectiveness in disease prevention and health promotion, the consumption of functional and nutraceutical foods has increased more and more. In this sense, the egg is included in this class of foods, as it is one of the most economical sources of protein for the human diet, it has in its composition lipids, vitamins and high quality minerals. Eggs have a high potential for enrichment with polyunsaturated fatty acids (PUFAs) by supplementing the diet of laying hens with ingredients that contain this type of fatty acid, resulting in increased deposition of omega-3 in the egg yolk. Fishmeal is an example of an ingredient that can be included in poultry diets, as it has a considerable amount of amino acids, vitamins and PUFAs. The inclusion of fishmeal in laying diets can improve the immune response of birds and humans, PUFAs help in the prevention and treatment of various diseases, decrease levels of circulating triglycerides and participate in the structure and function of the brain. In addition to easy inclusion in laying diets, fishmeal promotes rapid modification in the lipid composition of egg yolk and helps in the disposal of waste from agroindustry. A literature search was carried out on the internet of articles included in the inclusion of fishmeal in the diet of laying hens from 2005 to 2020 . The objective of this study was to find positive points that leverage the use of this by-product in poultry diets.
\end{abstract}

Keywords: Fish waste; Omega 3; PUFAs.

\section{Resumen}

Debido a su efectividad para prevenir enfermedades y promover la salud, el consumo de alimentos funcionales y nutracéuticos ha aumentado cada vez más. En este sentido, el huevo se incluye en esta clase de alimentos, por ser una de las fuentes de proteína más económicas para la dieta humana, teniendo en su composición lípidos, vitaminas y minerales de alta calidad. Los huevos tienen un alto potencial de enriquecimiento con ácidos grasos poliinsaturados (PUFA) al complementar la dieta de las gallinas ponedoras con ingredientes que contienen este tipo de ácido graso, lo 
que resulta en una mayor deposición de omega-3 en las yemas de huevo. La harina de pescado es un ejemplo de un ingrediente que puede incluirse en la dieta de las aves de corral, ya que tiene una cantidad considerable de aminoácidos, vitaminas y PUFA. La inclusión de harina de pescado en las dietas de las gallinas ponedoras puede mejorar la respuesta inmune de las aves y los humanos, los PUFA ayudan en la prevención y el tratamiento de diversas enfermedades, disminuyen los niveles de triglicéridos circulantes y participan en la estructura y función del cerebro. Además de su fácil inclusión en las dietas de las gallinas ponedoras, la harina de pescado promueve la modificación rápida de la composición lipídica de las yemas de huevo y ayuda a eliminar los residuos de la agroindustria. Se realizó una búsqueda bibliográfica en internet de los artículos incluidos en la inclusión de harina de pescado en la dieta de gallinas ponedoras de 2005 a 2020. El objetivo de este estudio fue encontrar puntos positivos que apalancan el uso de este subproducto en dietas avícolas.

Palabras clave: Desechos de pescado; Omega 3; PUFA.

\section{Introdução}

A busca por uma vida mais saudável tem estimulado os consumidores na busca por alimentos que contenham substâncias benéficas ao organismo. Nesse sentido, os ovos enriquecidos têm recebido atenção (Liang et al. 2020), pois apresentam alto potencial para enriquecimento com PUFAs, uma vez que são consumidos pela população mundial, seja in natura ou processados e o perfil lipídico da gema dos ovos pode ser alterado através da suplementação da dieta de galinhas poedeiras com alimentos que contenham esse tipo de ácido graxo (Santos et al. 2019).

O motivo pelo qual desejou-se enriquecer os ovos com PUFAs é a presença do ômega-3 na gema dos ovos, pois é conhecido que ele apresenta muitas vantagens quando é incluído na dieta, não somente na dieta humana, mas também na dieta das aves, pois ele é responsável pelo controle e prevenção de algumas doenças.

Diante do que foi exposto, o presente estudo teve como objetivo fazer uma revisão bibliográfica integrativa sobre a utilização da farinha de peixe como ingrediente na alimentação de aves poedeiras. Onde será dado maior enfoque às características desse ingrediente como agente antioxidante, na transmissão de PUFA's aos ovos e possíveis implicações na qualidade dos ovos.

\section{Referencial Teórico}

\subsection{Utilização de subprodutos de peixe na avicultura}

Desde o momento da captura, industrialização e até a comercialização, grande parte da produção de peixes é perdida gerando elevada quantidade de resíduos. Estes por sua vez, são resíduos esses que são descartados de maneira incorreta em corpos d'água ou depositado em lixões urbanos. Nesse sentido, tecnologias que reaproveitem esses tipos de subprodutos têm sido estudadas como alternativas para reduzir problemas como estes (Mousavi et al. 2013).

Essa quantidade considerável de resíduos representa um potencial significativo para que sejam utilizados na alimentação animal (Arruda 2017). O uso de resíduos de peixes em dietas avícolas é comum em regiões que apresentam barreiras logísticas para grãos e alimentos de alto custo (Cruz et al. 2016).

Um alimento alternativo, de origem animal ou vegetal, é recomendável quando existe um potencial real de inclusão na alimentação, ou seja, quando sua inclusão deste alimento diminui o custo da alimentação, quando tem valor biológico semelhante ou melhor que o alimento convencional e ainda está disponível no mercado (Silva et al. 2017).

A transformação desse resíduo em subprodutos torna-se uma opção de renda extra para as indústrias de beneficiamento de pescado. A farinha, por exemplo, é utilizada principalmente na alimentação animal, uma vez que os peixes são ricos em PUFAs, cálcio e fósforo. Esse tipo de subproduto tem potencial para utilização em ração de galinhas poedeiras quando se visa a obtenção de ovos nutricionalmente enriquecidos com PUFA n-3 (Teodoro et al.2019) melhor produção de ovos, conversão alimentar, peso do ovo, relação gema: albumina, redução dos custos de alimentação e produção (Silva et al. 2017). 
Nos últimos anos, técnicas modernas de extração desses resíduos, recuperam alimentos que iriam para o descarte podendo fornecer nutrientes úteis na nutrição animal e no bem-estar humano (farmacêutica, cosméticos, nutracêuticos), como proteínas, ácidos graxos, peptídeos, quitina, colágeno, carotenoides e minerais (Bruno et al. 2019).

A avicultura nos últimos anos foi considerada como uma das atividades da pecuária mais desenvolvidas, devido aos seus avanços em genética, nutrição, saneamento e gestão. Sendo que um dos seus principais objetivos é converter de maneira eficiente e econômica matérias-primas que seriam descartadas em ingredientes a serem incluídos em dietas avícolas. Dietas que utilizam ingredientes alternativos, a baixo custo, podem ser formuladas para várias idades e espécies de aves (Pinheiro et al. 2012).

Inicialmente, Silva et al. (2017) encontraram um aumento no consumo de ração quando a farinha de subproduto de peixe foi incluída em dietas para aves, assim como Nogueira et al. (2014) associaram diretamente esse aumento de consumo à inclusão de produtos de origem animal que refletem positivamente na palatabilidade dessa dieta, uma vez que as aves possuem predileção por alimentos que contenham de médio a alto teor de lipídios. E quando essa farinha foi incluída em maiores quantidades na dieta, houve uma diminuição no consumo, podendo estar relacionada também ao alto teor de lipídios em sua composição. Neste caso, o aumento da proteína e o alto perfil lipídico da farinha de subproduto de peixe pode ter auxiliado no enriquecimento nutricional das dietas e a presença de uma variedade de nutrientes deste subproduto estimula a produção de ovos.

\section{2 Ácidos graxos polinsaturados ômega - 3 (PUFAS n-3)}

As gorduras possuem papel fundamental nas dietas, pois aumentam a densidade calórica para atender às necessidades nutricionais dos animais. Além da energia, a fonte de gordura pode fornecer diferentes tipos de ácidos graxos, que irá variar de acordo com a composição dessa gordura (Gasco et al. 2020).

Os ácidos graxos polinsaturados (PUFAs) são classificados principalmente em ômega três (n-3 ou linolênico) e ômega seis (n-6 ou linoléico), conhecidos como ácidos graxos essenciais, pois não podem ser sintetizados pelo organismo dos animais, incluindo humanos, sendo importantes para a manutenção da saúde. Os n-3 mais importantes são o ácido eicosapentaenoico (EPA), ácido docosahexaenoico (DHA) e ácido alfa-linolênico (ALA).

O aumento de DHA na alimentação de aves tem sido associado a melhoria no crescimento, fertilidade, imunidade e resistência óssea. Quando animais monogástricos recebem uma alimentação rica em ingredientes que contenham DHA, esse enriquecimento pode chegar às dietas humanas e também fornecer benefícios à saúde (Lee, Whenham \& Bedford, 2019). Ligados ao PUFA n-3 podemos citar melhorias nos efeitos de doenças cardiovasculares, diabetes, câncer, doença de Alzheimer, demência, depressão, retina e desenvolvimento neurológico e função imunológica (Shahidi \& Ambigaipalan, 2018). Devido à essas vantagens do PUFA n-3 para a saúde, tem-se aumentado o interesse no consumo desses ácidos graxos essenciais.

Antes de incluir algum ingrediente à dieta das aves é necessário verificar sua composição, pois nem todas as fontes de PUFA n-3 fornecerão a mesma quantidade desse ácido graxo. Ingredientes vegetais, como por exemplo farinha ou óleo de linhaça podem ser usados para enriquecer dietas com ácidos graxos n-3, porém o ácido $\alpha$-linolênico da linhaça requer alongamento e dessaturação para gerar o EPA e DHA, um processo limitado em animais (Kartikasari et al. 2012).

Uma fonte de origem animal muito conhecida são os peixes, pois são ricos em PUFAs e podem ser adicionados nas rações na forma de farinha ou óleo. 


\subsection{Porque adicionar PUFA n-3 às dietas de poedeiras?}

Normalmente as dietas para aves são à base de milho e outros grãos que contem muito pouco de ALA, enquanto que DHA e EPA são praticamente ausentes. Os óleos vegetais comumente utilizados (milho, soja, girassol) também possuem muita pouca quantidade de PUFAs n-3 (Okolelova, 2013).

Ao realizar esse tipo de suplementação é necessária atenção em relação à proporção n-6: n-3 que é recomendada inferior a 4, porém quando se inclui produtos de origem animal essa relação varia entre 10 e 15 (Kouba \& Mourot, 2011). Essa relação é importante para que não haja competição entre eles, pois a elongase e a dessaturase podem ser usadas em ambas as séries de PUFAs, assim como na biossíntese de moléculas envolvidas no processo de inflamação, resposta imune, regulação do crescimento da célula e controle da pressão arterial (Liang et al. 2020). Segundo (Shapira, 2010), a proporção de n-6: n-3 encontrada no ovo comum é muito maior do que é recomendado para ingestão humana.

O uso de subprodutos da indústria pesqueira incluídos à níveis próximos de $5 \%$ pode ser uma alternativa interessante na alimentação de poedeiras, pois pode fornecer melhorias na qualidade nutricional das dietas, otimizando os resultados de desempenho. A inclusão de farinha de subproduto de peixe em dietas de aves demonstrou melhorias na conversão alimentar (Silva et al. 2017).

A massa de ovo apresentou efeito linear positivo com o aumento da inclusão de farinha de subprodutos de peixe nas dietas, uma vez que a massa de ovo está diretamente relacionada a produção de ovos (Feijó et al. 2016). O mesmo foi encontrado por Hanna et al. (2013) que também verificaram o efeito significativo para massa de ovos através da inclusão de alimentos alternativos na ração.

Silva et al. (2017) avaliaram outros parâmetros relacionados à qualidade do ovo, como peso do ovo, porcentagem de gema, porcentagem de albumina, porcentagem de casca, altura da gema e altura do albúmen também foram observados. O melhor resultado para peso do ovo foi a inclusão de $0,85 \%$ da farinha de subprodutos de peixe, corroborando Miller et al. (2013) que avaliaram a inclusão de alimentos energéticos alternativos em dietas de galinhas poedeiras e concluíram que a inclusão destes alimentos aumentou o peso e o conteúdo interno e externo do ovo. Associados a esses resultados está o aumento da porcentagem de gema (31,39\%) ao nível de inclusão de 2,75\%.

Firman, Kamyab e Leigh (2008) relataram que a inclusão de alimentos que contenham médio ou alto teor de lipídios na ração para galinhas poedeiras está diretamente associada a alterações na percentagem de gema (mudanças no metabolismo lipídico) e na porcentagem de albúmen (influência no equilíbrio da energia proporção de proteína e, consequentemente, na deposição de albumina para sua formação). A altura da gema foi maior ao nível de $0,86 \%$ de inclusão, enquanto que para a altura do albumen, os melhores índices foram com a inclusão de 4,19\% de farinha de subprodutos de peixes nas dietas.

Em relação a qualidade da casca e na unidade Haugh não foram detectadas nenhuma diferença pela inclusão de farinha de subproduto de peixe na ração para galinhas poedeiras comerciais. Foi encontrada também uma significativa redução nos custos de alimentação e, consequentemente, nos custos de produção, onde maiores inclusões de farinha de subproduto de peixe nas dietas proporcionaram maior economia e menores custos de produção (Silva et al. 2017).

Rufino et al. (2015) também encontraram uma redução significativa no custo de produção em uma análise econômica da farinha de subproduto do Tucumã em dietas poedeiras em substituição ao milho.

Geralmente em dietas avícolas e suínas se incluem gordura animal ou vegetal, juntamente com outros ingredientes para fornecer os requisitos de energia para mantença e crescimento do animal. O tipo de gordura a ser usada tem forte relação com o custo, disponibilidade local, palatabilidade, digestibilidade e desempenho resposta (Kanakri et al, 2018). Não é muito comum a composição do ácido graxo ser um fator decisivo, porém a suplementação dietética de PUFA n-3 foi associada com o enriquecimento de produtos de origem animal e também com benefícios para a saúde de suínos e aves (Swiatkiewicz, ArczewskaWlosek \& Jozefiak, 2015). 
Liang et al. (2020) observaram que o peso corporal e a ingestão de alimentos foram aumentados em aves alimentadas com PUFA n-3 (óleo de peixe) em comparação com PUFA n-6 (óleo de girassol).

Galinhas poedeiras em sistemas de gaiolas apresentaram uma incidência de $15 \%$ a $55 \%$ de quebra de osso da quilha e $30 \%$ a $95 \%$ e galinhas sem gaiolas. Esses resultados podem ser devido à baixa resistência óssea e o sistema de habitação desses animais (Wilkins et al. 2011).

Toscano et al. (2015) também encontraram que aves alimentadas com uma dieta controle (sem PUFA n-3) tiveram maior incidência de fratura de quilha do que aves alimentadas com dieta contendo PUFA n-3.

\subsection{Ovos enriquecidos com PUFA n-3}

O conceito "ovo funcional ou enriquecido" se explica pelo seu efeito terapêutico e/ou profilático e que contenha substâncias bioativas (BAS). A escolha dessas BAS é determinada por alguns fatores como a sua deficiência na dieta humana, a eficiência da transferência da ração para o ovo, a estabilidade do conteúdo durante o processamento ou cozimento e a proporção diária fornecida (Surai, 2010).

O perfil de ácidos graxos da gema é dependente dos lipídeos presentes na dieta, dessa maneira é possível uma modificação lipídica da gema com BAS solúvel em lipídeos de maneira relativamente rápida, entre duas a quatro semanas (Arkhipov, 2007).

Para se ter sucesso no enriquecimento com PUFAs n-3 é necessário usar uma fonte com alta biodisponibilidade, que não tenha efeito negativo na saúde e bem-estar das galinhas poedeiras, na produção e qualidade dos ovos e, controle de PUFAS n-6- e n-3 na dieta e o produto final (Kavtarashvili et al. 2007).

A inclusão de fontes lipídicas nas dietas de poedeiras pode alterar a qualidade nutricional do ovo, principalmente o perfil de ácidos graxos da gema (Oliveira et al.2011). Alguns fatores como a idade da ave e a pigmentação da gema do ovo podem influenciar na correlação entre lipídios e a gema, uma vez que a maioria dos alimentos lipídicos possuem carotenoides (Gul et al. 2012).

Sendo assim, os diferentes tipos de fonte utilizados, bem como a qualidade e os níveis de inclusão dos alimentos lipídicos, são fatores que podem beneficiar a qualidade nutricional dos ovos, caracterizando-se como uma alternativa viável para a produção de alimentos enriquecidos e com maior valor agregado (Rodrigues et al. 2005).

Durante o armazenamento dos ovos, os lipídios presentes na gema podem ser hidrolisados por enzimas que estão presentes na própria gema do ovo, liberando ácidos graxos livres. Assim acontece a peroxidação lipídica e pode ser produzido hidroperóxidos e produtos de oxidação secundária, reduzindo o teor de lipídios presentes na gema (Liang et al. 2020).

A degradação lipídica pode causar a deterioração do conteúdo biológico dos ovos e alterar propriedades como sabor, aroma, textura, cor, valor nutricional e tempo de armazenamento (Saleh, 2013) entre outros.

O enriquecimento de ovos com ácidos graxos obtidos de óleos de origem animal ou vegetal é uma ferramenta positiva para a avicultura, porém o nível da inclusão deve ser adequado de maneira que não cause uma elevada degradação lipídica e reduza a qualidade sensorial desses ovos (Seibel et al. 2010). A oxidação lipídica aumenta linearmente com a concentração de PUFA e a estabilidade dos PUFA diminui à medida que o seu grau de insaturação aumenta (Cortinas et al. 2005).

Diante do exposto, os ovos enriquecidos com PUFA n-3 requer que sejam adicionados antioxidantes dietéticos para prevenir a oxidação lipídica e a vitamina E tem se mostrado muito eficiente, uma vez que ela também é uma substância bioativa que pode ser usada no enriquecimento de ovos (Nimalaratne \& Wu, 2015). A vitamina E previne que as gorduras sejam oxidadas antes da absorção melhorando a digestibilidade e evitando a oxidação antes da absorção (Nogueira et al. 2014). 
A suscetibilidade à estabilidade oxidativa de alimentos com alta proporção de PUFAs aumenta com o aumento das instaurações e podem levar a formação de produtos de oxidação que são prejudiciais às aves e são transferidos aos ovos, tendo um decréscimo mais rápido na qualidade durante o armazenamento e/ou cozimento (Kavtarashvili et al. 2007).

Esse fenômeno é menos provável quando é adicionado à dieta quantidades suficientes de antioxidantes (vitamina E, vitamina C e etoxiquina). Assim, ovos enriquecidos com PUFA n-3 foram estáveis durante o armazenamento na presença de antioxidantes (Ren et al. 2013; Lamas et al. 2016).

Liang et al. (2020) avaliaram ovos enriquecidos armazenados por 24 dias a $25^{\circ} \mathrm{C}$ e obtiveram como resultado, uma redução total da capacidade antioxidante e aumento nos valores de substâncias reativas ao ácido tiobarbitúrico (TBARS). Eles também mostraram que os ácidos graxos e a atividade antioxidante em ovos enriquecidos com PUFA n-3 foram mais estáveis durante o armazenamento por 24 dias a $4^{\circ} \mathrm{C}$.

\section{Metodologia}

Foi realiza uma pesquisa qualitativa segundo Pereira et al. (2018), onde artigos científicos foram classificados utilizando como tema principal a utilização da farinha de peixe na alimentação de aves poedeiras. A busca por eles foi realizada nas bases de dados Scielo, periódicos Capes, Research Gate, NCBI, Nature, PubMed e Google Acadêmico usando como palavras-chave Fish flour, poultry, enriched eggs. Como critérios de seleção dos artigos foram atribuídos: ano de publicação (de 2005 e 2020), idioma (português e inglês), artigos que relacionaram a farinha de peixe com poedeiras e que relataram a influência da farinha de peixe com a qualidade de ovos. Para exclusão, foram as referências fora dos anos estabelecidos, escrito em outros idiomas que não sejam o inglês e português e artigos que tenham objetivo diferente do que foi proposto nesse trabalho. Assim, foram encontrados 25 artigos utilizando as palavras-chaves nas bases citadas acima e, posteriormente 10 artigos foram selecionados para inclusão de algumas informações pertinentes ao assunto estudado contidas neles.

\section{Considerações Finais}

Devido ás mudanças de hábitos alimentares humanos na busca de uma saúde melhor, a demanda de produtos enriquecidos tem aumentado. Assim, os ovos enriquecidos com PUFA n-3 são produtos competitivos à essa demanda, uma vez que eles são fontes de vários nutrientes essenciais à nossa dieta, possuem um bom custo-benefício e são facilmente produzidos através da inclusão de PUFAs na dieta de galinhas poedeiras.

Os PUFAs n-3 são essenciais para a promoção de uma melhor saúde e prevenção de várias doenças humanas. Eles não são sintetizados em nosso organismo, portanto devem ser oriundos de nossa dieta.

A inclusão de ácidos graxos na dieta de aves, a níveis comercialmente aceitáveis, pode ser vantajosa tanto para os consumidores como para a indústria avícola (Shin et al. 2011). A aceitabilidade do consumidor (Ganesan, Brothersen \& Mcmaho, 2014) e o preço (Watters et al. 2012) são os maiores desafios enfrentados dentro da indústria pecuária.

A suplementação dietética com PUFAs não só melhora a qualidade do produto final, mas também melhora a resistência óssea das aves, o que está relacionado ao bem-estar desses animais. Eles melhoram a produção de ovos, o consumo de alimentos e outras funções fisiológicas que esses tipos de ácidos graxos possuem.

Assim como o ovo comum, os ovos enriquecidos necessitam de armazenamento refrigerado, para que suas propriedades organolépticas sejam mantidas. Em relação à inclusão da farinha de peixe nas dietas, a quantidade precisa ser adequada para que atenda às necessidades nutricionais em energia das aves e também possa ser transferida aos ovos. Lembrando que em altas concentrações ela pode transferir ao ovo o odor e sabor característicos. 
A farinha de peixe é um alimento que possui muitos nutrientes importantes para a nutrição animal, além de seu uso contribuir para que sejam escoados os resíduos de indústrias pesqueiras, agregar valor a um subproduto e aumentar a lucratividade tanto das agroindústrias como dos aviários.

Essas questões apontam que ainda há muitos trabalhos a serem a realizados a respeito do impacto ambiental do descarte desse tipo de resíduo, a quantidade a ser incluída sem que haja prejuízo as qualidades organolépticas dos ovos, mas que seja capaz de enriquecê-los com PUFAs n-3.

\section{Referências}

Arkhipov, A. V. (2007). Lipidnoe pitanie, produktivnost' ptitsy i kachestvo produktov ptitsevodstva [Lipid nutrition, poultry performance and quality of poultry products]. (in Russ.).

Arruda, M. C. F. (2017). Avaliação dos indicadores da política de pesca do programa zona franca verde: valorização e proteção ambiental. UFAM.

Bruno et al. (2019). Green and innovative techniques for recovery of valuable compounds from seafood by-products and discards: a review. Trends Food Sci Tech. 85:10-22.

Cortinas et al. (2005). Influence of the dietary polyunsaturation level on chicken meat quality: lipid oxidation. Poultry Science. 84:48-55.

Cruz et al. (2016). Perfil socioeconômico da Avicultura no setor primário do Estado do Amazonas, Brasil. Revista em Agronegócio e Meio Ambiente. 9 (2): 371 391.

Feijó et al. (2016). Farinha de cará (Dioscoreatrifida L) sobre o desempenho, qualidade do ovo e parâmetros bioquímicos de poedeiras comerciais leves. Revista Brasileira de Saúde e Produção Animal. 17(3): 413-423.

Firman, J. D., Kamyab, A. \& Leigh, H. (2008). Comparison of fat sources in rations of broilers from hatch to market. Int J Poultry Science. 7:1152-5.

Ganesan, B., Brothersen, C. \& Mcmahon, D. J. (2014). Fortification of foods with omega-3 polyunsaturated fatty acids. Crit Rev Food Sci Nutr. 54: 98-114.

Gasco et al. (2020). Insect and fish by-products as sustainable alternatives to conventional animal proteins in animal nutrition. Italian Journal of Animal Science. 19 (1): $360-372$.

Gul et al. (2012). The effect of diferente levels of canola oil on performance, Egg shell quality and fatty acid composition of laying hens. International Journal of Poultry Science, 11(12): 769-776.

Hanna et al. (2013). Bioefficacy of the Copaiba Oil (Copaifera sp.) In Diets of Laying Hens in the Second Production Cycle in Humid Tropical Climate. International Journal of Poultry Science. 12(11): 647-652.

Kanakri et al. (2018). The effect of diferente dietary fats on the fatty acid composition of several tissues in broiler chickens. Eur J Lipid Sci Technol. 120:1700237.

Kartikasari et al. (2012). Dietary alpha- linolenic acid enhances omega-3 long chain polyunsaturated fatty acid levels in chicken tissues. Prostaglandins Leukot Essent Fatty Acids. 87:103-9.

Kavtarashvili et al. (2017). Functional egg production. I. The role of $\omega$-3 polyunsaturated fatty acids (Review). Poultry: since and Technologies. Agricultural Biology, 52 (2): 349-366.

Kouba, M. \& Mourot, J. (2011). A review of nutritional effects on fat composition of animal products with special emphasis on n-3 polyunsaturated fatty acids. Biochimie. 93:13-7.

Lamas et al. (2016). Desenvolvimento tecnológico de ovoprodutos funcionais por uma adição de óleo enriquecido com ácido graxo poliinsaturado n-3. CyTA Journal of Food. 14: 289-295.

Lee, S. A., Whenham, N. \& Bedford, M. R. (2019). Review on docosahexaenoic acid in poultry and swine nutrition: Consequence of enriched animal products on performance and health characteristics. Review Article. Animal Nutrition. (5): $11-21$.

Liang, K., Zu, H., Xiaohong, W. (2020). Effect of storage on n-3 PUFA-enriched eggs. Cyta-Journal of Food. 18 (1): $102-107$.

Miller et al. (2013). Farinha do resíduo de tucumã (Astrocaryum vulgare Mart.) na alimentação de poedeiras. Revista Acadêmica: Ciências Agrárias e Ambientais. 11 (1): 105-114.

Mousavi et al. (2013). Silage production from fish waste in cannery factories of Bushehr city using mineral acid, organic acid, and biological method. International Journal of Agriculture and Crop Sciences, 6 (10): 610-616.

Nimalaratne, C. \& Wu, J. (2015). Hen egg as an antioxidant food commodity: A review. Nutrients. 7 (10): $8274-8293$.

Nogueira et al. (2014). Suplementação de óleo de dendê (Elaeisguineenses Jaquim) na alimentação de poedeiras em clima tropical. Revista Académica: Ciências Agrarias e Ambientais. 12 (2): 103-111.

Okolelova, T. M. (2013). Ptitsevodstvo. 5: 15-19 (in Russ.). 
Research, Society and Development, v. 10, n. 8, e20810817115, 2021

(CC BY 4.0) | ISSN 2525-3409 | DOI: http://dx.doi.org/10.33448/rsd-v10i8.17115

Oliveira et al. (2011). Effects of the use of soybean oil and animal fat in the diet of laying Henson production performance and egg quality. Ciência e Agrotecnologia, 35 (5): 995-1001.

Pereira, A. S. et al. Metodologia da pesquisa científica. 2018 UFSM. https://repositorio.ufsm.br/bitstream/handle/1/15824/Lic_Computacao_MetodologiaPesquisa-Cientifica.pdf? sequence $=1$.

Pinheiro et al. (2012). Desempenho e qualidade dos ovos de poedeiras comerciais leves submetidas a dietas contendo torta de nabo forrageiro. Ciências Agrárias. 33 (4): $1555-1564$.

Ren et al. (2013). Estabilidade oxidativa de ovos enriquecidos com ácidos graxos poliinsaturados ômega-3. Journal of Agricultural and Food Chemistry. 27: $11595-11602$.

Rodrigues et al. (2005). Desempenho, qualidade da casca e perfil lipídico de gemas de ovos de poedeiras comerciais alimentadas com níveis crescentes de óleo de soja no segundo ciclo de postura. Acta Scientarium Animal Science, 27 (2): 207-212.

Rufino et al. (2015). Análise econômica da inclusão de farinha do resíduo de tucumã (Astrocaryum vulgare Mart) na alimentação de poedeiras comerciais. Revista Brasileira de Saúde e Produção Animal. 16 (1): 1-9.

Saleh, A. A. (2013). Effects of fish oil on the production performances, polyunsaturated fatty acids and cholesterol levels of yolk in hens. Emirates. Journal of Food and Agriculture, 25 (8): 605-612.

Santos et al. (2019). Ácidos graxos poli-insaturados na dieta de poedeiras: impactos sobre a qualidade dos ovos e saúde humana. Medicina Veterinária (UFRPE), Recife, 13 (3): 406-415.

Seibel et al. (2010). Caracterização sensorial de ovos de codornas alimentadas com dietas modificadas. Ciência Tecnologia de Alimentos. 30 (4): $884-889$.

Shahidi, F.\& Ambigaipalan, P. (2018). Omega-3 polyunsaturated fatty acids and their health benefits. Annu Rev Food Sci Technol. 9:345 - 81.

Shapira, N. (2010). Every egg may have a targeted purpose: Toward a differential approach to egg according to composition and functional effect. World's Poultry Sci. J. 66(2): 271-284.

Shin et al. (2011). Efeitos da combinação dietética de ácido linoléico conjugado e óleo de linhaça ou de peixe na concentração de ácido linoléico e araquidônico na carne de aves. Poultry Science. 90 (6): 1340-1347.

Silva et al. (2017). Farinha de subproduto de peixe em dietas para galinhas poedeiras comerciais. Acta Scientiarum. Ciências Animais. Maringá, 39 (3): 273 279.

Surai, P. (2010). Kombikorma, 6: 95-96 (in Russ.).

Swiatkiewicz, S., Arczewska-Wlosek, A. \& Jozefiak, D. (2015). The relationship between dietary fat sources and immune response in poultry and pigs: an updated review. Livest Science. 180: 237-46.

Teodoro et al. (2019). Desidratação de resíduos de peixes como forma de agregação de valor e sustentabilidade ambiental. VI SIGERA - Simpósio internacional sobre gerenciamento de resíduos agropecuários e agroindustriais. Florianópolis.

Toscano et al. (2015). The effects of long (c 20/22) and short (c18) chain omega-3 fatty acids on keel bone fractures, bone biomechanics, behavior, and egg production in free-range laying hens. Poultry Science. 94: 823-35.

Watters, et al. (2012). A cost analysis of EPA and DHA in fish, supplements and foods. J Nutr Food Science. 2:1 - 5.

Wilkins et al. (2011). Influence of housing system and design on bone strength and keel bone fractures in laying hens. Vet Rec. 169:414. 